\title{
Survey Study of Centre Pivot Irrigation System in Northern State (Sudan)
}

\author{
Asim Osman Elzubeir \\ Faculty of Agricultural Science, University of Dongola, Dongola, Sudan \\ Email address: \\ asimosman11@ymail.com \\ To cite this article: \\ Asim Osman Elzubeir. Survey Study of Centre Pivot Irrigation System in Northern State (Sudan). International Journal of Science and \\ Qualitative Analysis. Vol. 4, No. 1, 2018, pp. 27-33. doi: 10.11648/j.ijsqa.20180401.15
}

Received: December 22, 2018; Accepted: January 16, 2018; Published: February 5, 2018

\begin{abstract}
A survey study was carried out in April 2015 to identify application of centre pivot irrigation system in Northern State (Sudan) and to find out the major problems facing its use under a local conditions of the State and make recommendations to address them. The study included 76 centre pivot machines distributed in nine projects in different locations in the State. The required data was collected by questionnaire and field visits to the sites of the case study. Results of the study revealed that there were some problems facing the use of centre pivot irrigation system under the local conditions of the State, which can be solved by providing trained and skilled labour to operate the system in these projects. A centre pivot irrigation system as a modern technology is promising to come into use in Northern State (Sudan).
\end{abstract}

Keywords: Irrigation, Sprinkler Irrigation, Centre Pivot Irrigation, Northern State (Sudan)

\section{Introduction}

Irrigation is generally defined as the application of water to soil for the purpose of supplying the moisture essential for plant growth or to insurance against short duration drought [1]. Many irrigation methods have been introduced and developed in the world with the aim of developing agriculture and enhancing agricultural production. Among these methods, sprinkler irrigation is the most important one and defined as the method of applying irrigation water which is similar to natural rainfall. Water is distributed through a system of pipes usually by pumping. It is then forced under pressure through small nozzles which gets broken up into droplets sprayed into the air and irrigated entire soil surface. The size of these droplets depends on nozzle diameter and operating pressure of the system [2]. There are many types of sprinkler irrigation due to the varying differences in types of crop, soil, climate and topography. Centre pivot irrigation system is one of the most important of these systems.

Application of centre pivot irrigation system is suitable for many field conditions. Due to great flexibility of this system and possibility to control its operation with high efficiency, it can be used to irrigate most crops and adapted to nearly all irrigable soils and under most climatic conditions. Nutrients and chemicals can be applied through this system
(Fertigation and Chemigation). Also, the system doesn't require large number of labour for operation compared with other irrigation methods [3].

Northern State of Sudan is characterized by a large agricultural lands (5 $880000 \mathrm{ha}=14$ millions feddans) and climatic conditions suitable for production of unlimited list of field and horticultural crops. However, low population density (2 persons $\left./ \mathrm{km}^{2}\right)$ [4] has seriously affected the State from various developmental aspects, and is reflected negatively in the scarcity of labour which is one of the most important factors of production. This situation makes application of modern agricultural technologies is an inevitable option to meet the large horizontal expansion of agricultural land use and helps to maximize the return of unit area of agricultural land.

The agricultural expansion requires adoption of modern irrigation systems such as centre pivot irrigation system, but introduction of new irrigation system not previously applied in the area leads to unexpected complications (technical, economic and social) if not accompanied by study [5]. Therefore, a survey of a group of centre pivot irrigation machines was conducted in some locations of Northern State (Sudan). The study aimed to:

1. Identify the design characteristics and operational features of centre pivot irrigation machines in the State. 
2. Identify main problems facing the use of centre pivot irrigation system under local conditions in the State and developing solutions to address them.

3. Adjust some recommendations to contribute in the widespread use of the system in the State.

\section{Materials and Methods}

A questionnaire was designed to conduct a survey study to identify features of centre pivot irrigation system used in the Northern State (Sudan), as well as to identify most important problems facing application of this system under the local conditions in the State and to develop some recommendations for addressing them to increase efficiency of using centre pivot irrigation system, rationalization of irrigation water use and to increase productivity of cultivated crops. To achieve these objectives, some projects applying this system were identified in a survey conducted in April 2015 using GOOGLE EARTH APP to locate these projects.

The study included 76 centre pivot irrigation machines distributed in different locations in the State. The data required in the questionnaire were obtained in nine projects that applying centre pivot irrigation system through field visits to these projects. Data and information were collected using the case study method. The questionnaire included five parts:

- Part one: data about the project; such as name, geographic location, owner type, establishment date, soil type, wind speed and direction in the site.

- Part two: data about centre pivot irrigation machine in terms of manufacturer name, machine age, number of machines in the project, number of towers in each machine, type of lateral line material, the impact of the line with corrosion and extent of the impact, location of corrosion in pipeline, time of maintenance of pipes and corroded joints and when they were changed.

- Part three: data about the pump and mainline used to pump irrigation water to indicate type and capacity of the pumps, location of these pumps, type of pipe material and diameter, determination of locations of corrosion in pipe and period during which corrosion problem occurred. Also, identification of irrigation water type and its source to reflect importance of water and its salinity on corrosion of used irrigation pipes.

- Part four: data on operation, evaluation and maintenance of the irrigation system in terms of number of operating hours per day and season, cultivated crops type, agricultural cycle, irrigation scheduling, field evaluation and maintenance and when they were done.

- Part five: determination of most problems facing projects with application of centre pivot irrigation system.

After data were collected and analyzed, percentages were used to analyze descriptive data to indicate features of centre pivot irrigation machines as well as to identify most important problems facing their users under a local conditions in the State and to develop some suggestions to address them and a set of recommendations for using the system optimally and reducing maintenance and repair costs.

Some similar studies had been referred, in the same field in other countries, particularly the research entitled: Evaluation the performance and modification of centre pivot irrigation systems under Saudi Arabia conditions [6].

\section{Results and Discussion}

Table 1 presents names of studied projects, owner type and number of irrigation machines in the project. It is clear that private sector accounts for largest number of centre pivot machines by $55 \%$ which reflects the trend of this sector to adopt modern technologies to obtain the highest return of agricultural investment, followed by governmental projects (37\%) and shareholding companies (8\%). Figure 1 shows geographic location of projects under study.

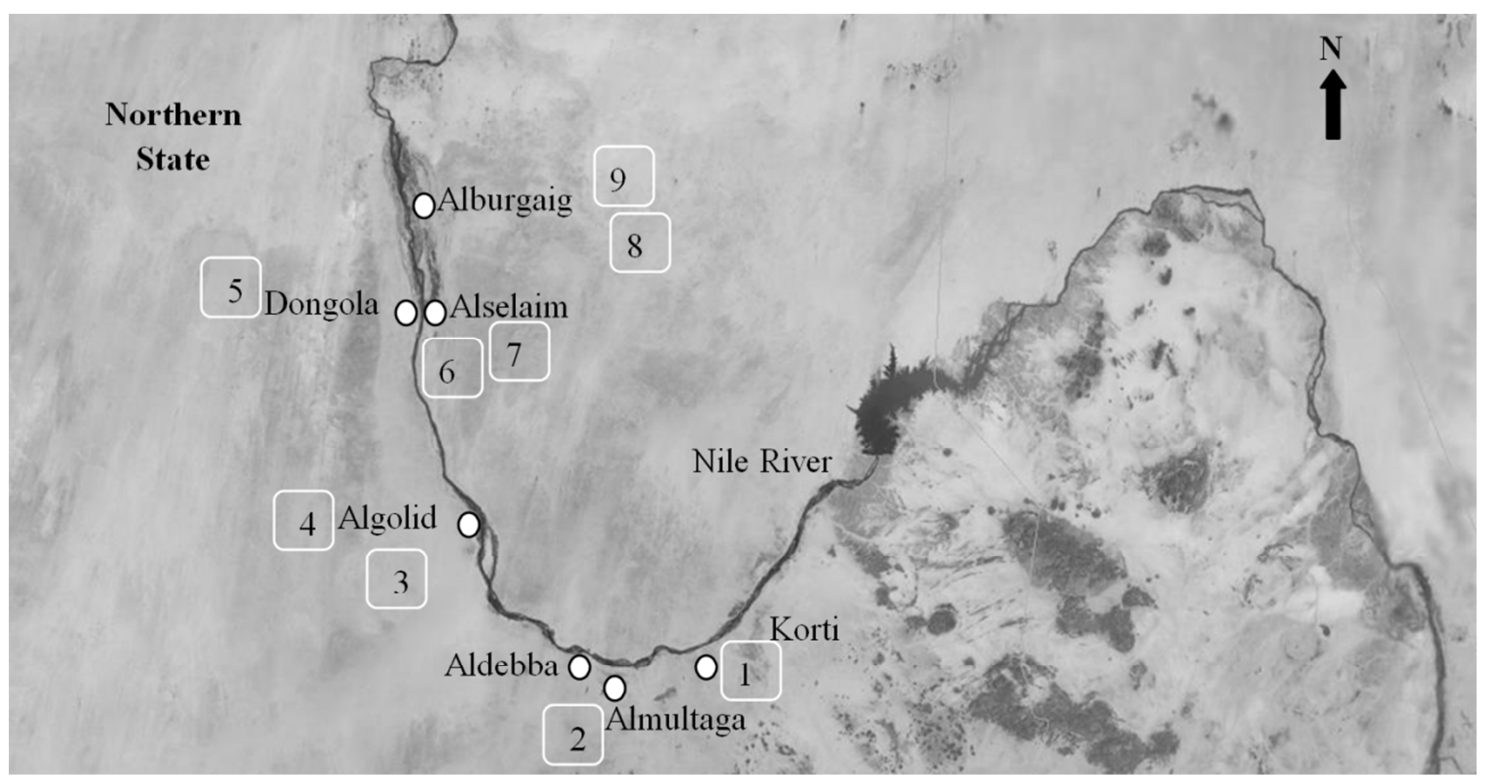

Figure 1. Geographic location of surveyed projects (Note: Project number as in Table 1). 
Table 1. Projects under survey (name, owner type and number of centre pivot machines in the project).

\begin{tabular}{llll}
\hline Project number & Project name & Owner type & Number of centre pivot machines in the project \\
\hline 1 & New Amri Agricultural Project & Governmental & 20 \\
2 & New Hamadab Agricultural Project & Governmental & 8 \\
3 & Shiakhat Albakri Company Project & Shareholding & 1 \\
4 & Alqanaa Agricultural Company Project & Private & 2 \\
5 & Binna Agricultural Project & Shareholding & 1 \\
6 & Alzubarah for Agricultural and Livestock Production & Private & 25 \\
7 & Alwaha and Alzahra Agricultural Project & Shareholding & 4 \\
8 & Azhari Abdel Haleem Agricultural Project & Private & 4 \\
9 & Abu Almunzir Agricultural Project & Private & 11 \\
\hline
\end{tabular}

Results of the questionnaire clarified that conditions in all surveyed projects are suitable for the application of centre pivot irrigation system in terms of soil type, topography and wind speed and direction. Soil ranged from clay, sandy and silt, and flat or relatively flat areas with some sand dunes as in some projects. Wind is north to northeasterly with medium speed.

Although $44 \%$ of surveyed projects were established in last century but they had only recently used centre pivot system. Also, 33\% of projects are using only centre pivot irrigation system since their establishment.

The examined centre pivot irrigation machines had different ages ranging from two to nine years at time of the study (see Figure 2). The first centre pivot machine was installed in the year 2006.

Results of the study observed that all centre pivot machines were produced by Alkhorayef company of Saudi Arabia under the trade name of Almotowar and had been installed by manufacturer's agent in Sudan with after-sale services during warranty period, training of operating team and provide periodic maintenance and spare parts upon request.

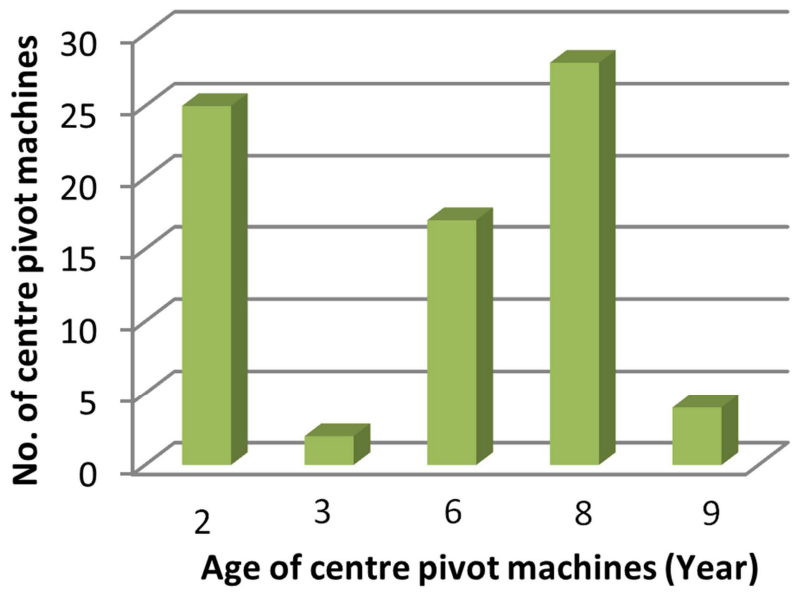

Figure 2. Age of studied centre pivot machines.

Figure 3 shows that centre pivot machines with seven towers was most common, followed by eight towers, nine towers and six towers by $75 \%, 16 \%, 8 \%$ and $1 \%$ respectively.

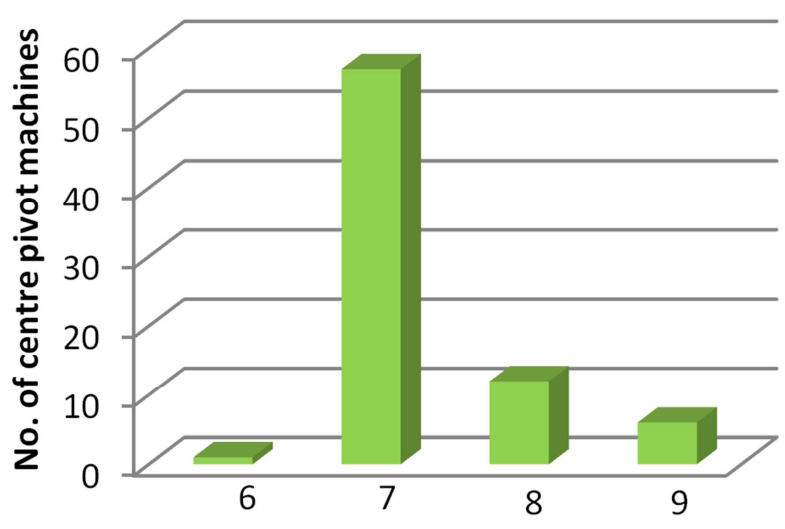

No. of towers in centre pivot machines

Figure 3. Number of towers in surveyed centre pivot machines.

Some centre pivot machines had been modified from their original factory configuration; as to change transmission shaft due to difference in sizes in one project and adding two towers to cover the target area in other project. Modifications in centre pivot machines by owners of projects can lead to low performance level of irrigation system, so such modifications should be done under supervision of those with sufficient experience and considerable skill to operate the system.

Data of the study indicated that type of lateral pipelines material used in all centre pivot machines was galvanized steel. These pipes were affected by corrosion after about 2- 3 years of use in $67 \%$ of centre pivot machines in the studied projects. The most affected parts in spray line were the joints; joints of the beginning of spray line were the most affected by corrosion, and corroded pipes were maintained immediately after the problem occurred.

The survey illustrated that all centre pivot irrigation machines used rotary sprayers which are the most widely used in the world, especially that have slowly rotation due to their specifications (characterized by large radius and low spray density) [7]. One of the negative aspects of centre pivot irrigation system is its circular pattern which is contrary to the nature of most projects that are usually either square or rectangular. Overhang after the last tower or end gun mounted at the last lateral can be applied to increase irrigated area by making efficient use of all areas [8]. It is obvious from Fig. 4 that all machines including overhang with length of 2.5- 12 meters, but the most common length was 10 
meters by $39 \%$ of number of machines followed by a length of 2.5 meters by $33 \%$.

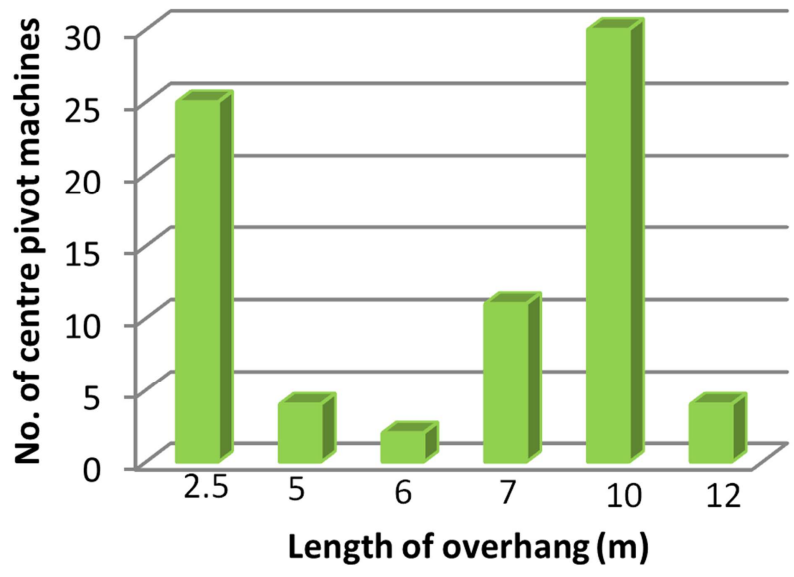

Figure 4. Length of overhang in studied centre pivot machines.

Results of data collected from the projects showed that pressure of sprayers was checked in $99 \%$ of centre pivot irrigation systems and not done in only $1 \%$ of them. The period of checking sprayers pressure was different between projects. The used sprayers were operated at low pressure close to soil surface to reduce evaporation losses as well as decrease operation cost due to low operating pressure necessary. Also, maintaining of sprayers pressure at appropriate level leads to increase uniformity of centre pivot irrigation system.

The results of the questionnaire indicated that $99 \%$ of used pumps had power of $75 \mathrm{hp}$ and $1 \%$ of $55 \mathrm{hp}$. Pumps were located outside centre pivot machine in $86 \%$ of machines and at the centre of the machine in $14 \%$. Type of all pumps was centrifugal pump and source of energy to operate them was diesel in $58 \%$ of machines and electricity in $42 \%$. Type of mainline material was galvanized steel in all machines with diameters of 8 and 10 inches by $89 \%$ and $11 \%$ respectively. The most affected parts of suction pipe were the submersible part of the pipe and the joints were most corrosive. The suction pipe was changed in one project after two years of use due to irrigation water salinity.

The source of used irrigation water by centre pivot systems according to surveyed projects is shown in Fig. 5, 64\% of centre pivot machines derived water from Nile River by canals, $36 \%$ of the machines used groundwater from boreholes; as one well for each machine which decreased hazards of affecting irrigated area when failure of a pump or motor of the well. Water from canals not usually found in a completely pure state, but contains suspended substances such as impurities, grasses and algae that spread in canals. All groundwater used in irrigation was characterized by a moderate salinity which began to change with period length of use. The survey found that only two projects had water reservoirs with different capacities.
Groundwater Nile water

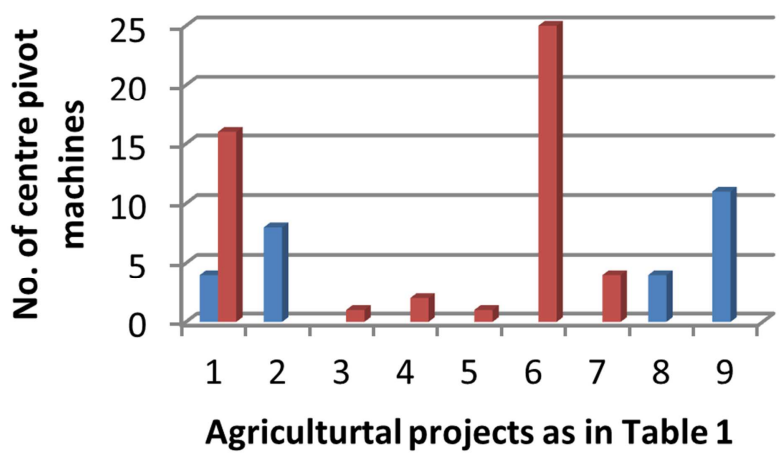

Figure 5. Source of irrigation water used by surveyed centre pivot machines.

The addition of fertilizers and certain plant protection chemicals through irrigation water is used as economically efficient and efficiently method to apply these substances appropriately [9]. Therefore, all studied projects added fertilizers and chemicals to irrigation water by means of centre pivot irrigation system. Fertilizers and chemicals were added at different intervals in each season or after each cut in some alfalfa-grown projects.

Figure 6 presents the number of operating hours per day for centre pivot irrigation systems. The maximum operating period per day was 15 hours, followed by 14 hours and up to 24 hours. It was also found that number of working hours in season varied according to cultivated crop type.

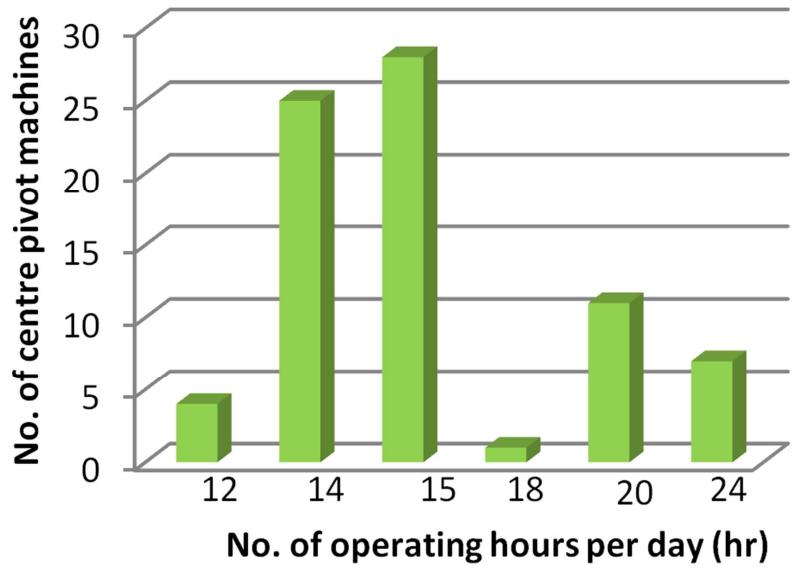

Figure 6. Number of operating hours per day for studied centre pivot machines.

All projects carried out emergency and periodic maintenances of centre pivot machines. Emergency maintenance was performed immediately after the problem occurred. Periodic maintenance was carried out every season in $86 \%$ of surveyed machines and annually in $14 \%$ of the machines. In most projects, labourers in the project performed maintenance of both types. In some cases, centre pivot machine manufacturer agent participated in periodic maintenance. Maintenances of centre pivot irrigation system contribute to increasing performance and uniformity of the system. Previous studies have shown that maintenance of centre pivot irrigation system has an effective role in raising 
performance of centre pivot irrigation system. Also, an increase in values of efficiencies of machines and coefficients of uniformity of water along spray line and rationalization of irrigation water after maintenance of centre pivot irrigation machines can be achieved [10].

Eight surveyed projects followed agricultural cycle system and all projects carried out irrigation scheduling using different tools; field observations (30\% of the machines), monitoring soil moisture $(33 \%)$ and tracking weather conditions (37\%). Three projects had their own meteorological station. Irrigation scheduling is managerial process aimed to determining when to irrigate and the amount of crop water requirement to maximize crop yield and return. Irrigation scheduling is necessary to rationalize water, energy and others substances e.g. fertilizers, which results in lower production costs and thus reduces overall cost of operating centre pivot machines [11].

The results of data showed that water application efficiency was evaluated in $99 \%$ of centre pivot machines under study and evaluation was not carried out in only one machine. The evaluation was done every season in $91 \%$ of centre pivot machines and annually in $8 \%$ of the machines. A periodic evaluation of irrigation system is recommended to detect problems that may not readily visible, and to confirm that the system is applying the amount of water it was designed to apply [12]. High performance efficiency indicates that there are no problems in irrigation system management and/or use and design efficiency of the system. A highly efficient irrigation system improves productivity and reduces variation in productivity within the same project. Also, it reduces loss of necessary elements for crop by runoff in whole or parts of project due to non-uniformity in irrigation water.

Engineers and technicians were responsible for operating of centre pivot machines in $37 \%$ of machines under study or engineers only in $20 \%$ or technicians only in $2 \%$ or workers only in $1 \%$. Centre pivot system operators should be considered in terms of selection and training, centre pivot machines can become tools for wasting water due to poor design and irresponsible administration and lack of application of crop water requirements in irrigation [13]. The operation of these machines was done manually and irrigation system obtained energy from the national electricity network in $42 \%$ of the machines or electricity was provided by on-site generation (generators) in 58\% of them which constitutes additional burdens due to high cost of diesel and frequent breakdown in diesel engines.

Figure 7 shows type of cultivated crops under centre pivot systems and their cultivated areas (season 2012/13) in the studied projects. Cultivated crops were alfalfa, wheat and potato by $60 \%, 38 \%$ and $2 \%$ of cultivated areas respectively. Centre pivot irrigation system in New Hamadab project (Project No. 2 in Table 1) was compared with surface irrigation used in experimental farm in the same project and considered traditional farmers farms as a reference and wheat yield in these sites as an indicator of experiments [14].Yield and growth parameters had significantly differences due to irrigation system. Productivity of wheat under centre pivot system, experimental farm and traditional farms were 1532 , 464 and $159 \mathrm{~kg} / \mathrm{fed}$ respectively. Also, centre pivot irrigation system gave better productivity of wheat in Alwaha and Alzahra project (Project No. 7 in Table 1) and its productivity improved by $72 \%$ compared with wheat yield under surface irrigation in the area (3.48 and 2.02 ton/ha respectively) [15].

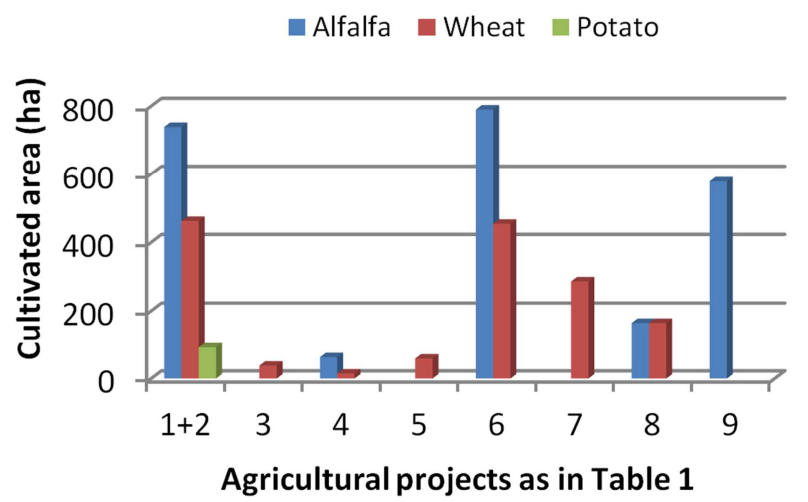

Figure 7. Crops type and cultivated areas using centre pivot system (season 2012/13).

The number and type of labour in projects applying centre pivot system is illustrated in Fig. 8.

Engineer Technician Worker $\square$ Trained Worker

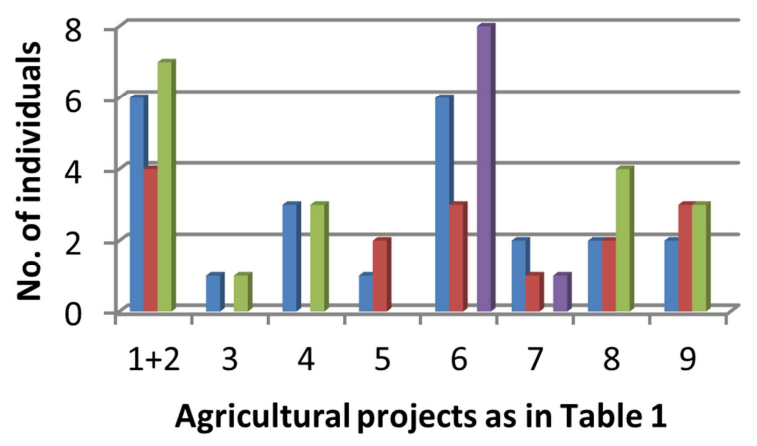

Figure 8. Type and number of manpower in surveyed projects.

Comparing area irrigated using centre pivot system in season 2012/13 with operation-based manpower was equivalent to 60 ha per capita. Thus, centre pivot system reducing labour requirements and decrease cost of manpower which is most important benefit of the system. Automation of irrigation systems can reduce cost of manpower to $90 \%$ compared to other systems [8].

Although the age of $58 \%$ of studied centre pivot irrigation machines were nine years or less at the time of study and relatively new, and through field visits to machines sites and interviews with machines operators, some problems encountered under conditions of Northern State (Sudan) as follows:

1. Frequent power cut which necessitate restart of electrically driven machines. In some cases, sudden interruption of electrical current led to failures in control devices of the sprayers. 
2. Fuel was not available permanently and diesel operating system was more expensive.

3. Frequent breakdown of diesel engines.

4. Lack of spare parts in vicinity of projects which required to be obtained from the agent and took additional time.

5. Tower tracks in muddy wetlands led to drift of centre pivot machine from the track or stopped motion in tires (wheel rutting), and sometimes damaged the tires or gearbox or transmission shaft.

6. Lack of paved service roads to reach the centre and the end of some centre pivot machines.

7. Roughness of roads lead to the projects, causing delay in arrival of services and other supplies.

8. Accumulation of salts on soil surface in one of the examined projects.

9. Surface runoff of irrigation water in clay soils especially in lowlands.

10. Broken or clogging of sprayers' heads due to presence of suspended substances such as salts in irrigation water, sediment deposits, sand or algae.

11. Accumulation of impurities, weeds and algae within canals led to inefficient water pumping.

12.Projects that derived irrigation water from Nile River had been affected by availability of a large quantity of silt led to damage of valves during flood period.

13. Some projects had been affected by desertification (sand dunes).

14. Water leakage from some joints of spray line due to corrosion in some parts.

By reviewing these problems and even can using centre pivot irrigation system in an optimal method to reduce costs of maintenance and repair, some of necessary treatments can be proposed, these are:

1. Solving problem of frequent power cut with competent authorities or making necessary precautions by providing self-running generators at sudden interruption of electricity during operation of centre pivot irrigation machines.

2. Replace diesel-powered machines with electrically powered to reduce operation cost and eliminate of frequent faults of diesel engines.

3. Provision of consumable spare parts long before beginning of season.

4. Checking tower tracks before operating machine and paving it well, and filling of tracks in dirt concrete especially in clay soils, and prefer not to plough towers tracks except for necessary of presence of shrubs or weeds.

5. Use specially designed semi-circular sprayers near the wheels to avoid being wetted especially in clay soils.

6. Paving service roads for all centre pivot irrigation machines to facilitate operation works and follow-up.

7. Paving of roads leading to projects to facilitate motion to/from projects.

8. Overcoming problem of salinity on soil surface in some projects by choosing optimal treatment method such as leaching accumulated salts down the profile, adding chemicals or cultivating crops that tolerance to soil salinity.

9. In case of soils with slow permeability (clay soil), this increases surface runoff in some low locations in the project. Runoff from centre pivot irrigation can be controlled by changing the optimal speed control setting to match water application to soil infiltration. The maximum recommended soil slope for centre pivot irrigation system is $15 \%$. However, centre pivot systems should be designed and managed sufficiently carefully in sloping lands to avoid problems associated with variations in pressure and surface runoff that can significantly affect system efficiency [16].

10. Selection of well-manufactured sprayers and more suitable for nature of soil, crop and climatic conditions of the area. Sprinkler irrigation is invented over 60 years ago and currently there are more efficient types of sprayers. Also, checking of sprayers pressure before operating machine and during operation and making sure not to be clogged and replace damaged one and cleaned when necessary by following appropriate methods that help to keep these ends clean constantly.

11. Valve shall be installed at the end of lateral and needs to be opened every time the machine is re-operated or at least twice a week to clean the spray line from sediments or sand that are present within irrigation water.

12. Use suitable filtration devices with periodic cleanliness. Mesh filter can only be used if water source is wells or sand filter is added together with mesh filter in case of surface water or surface tanks.

13. Installation of sedimentation basins for water purification especially during Nile River flood.

14. Cultivation of windbreaks in projects affected by desertification to reduce soil erosion and adverse effect of wind on uniformity efficiency and distribution.

15. Regular maintenance of different parts is important for maintaining system in good condition. Thus, prolonging life of machine and maintaining good performance levels to ensure system efficiency and no change in design elements such as pressure and water application rate will be happened.

\section{Conclusions}

Results of the study concluded that:

1. Design and operational features of centre pivot irrigation systems in Northern State (Sudan) are very similar in most projects which under similar climatic conditions, soil, topography and cultivated crops.

2. There are several problems that had been identified under application of centre pivot irrigation systems in the State, but can be easily overcome and solved if trained labour and highly qualified technicians are found. 


\section{Recommendations}

Centre pivot irrigation system as one of modern irrigation systems is promising to be widely used and deployed in Northern State of Sudan [17]; therefore the following recommendations can be drawn:

1. The system should be reliable and fast-fixable in field. Breakdown of centre pivot system for several days during maximum water requirement of crop can lead to loss of yield or significantly reduced production.

2. Encouraging investors in agricultural sector to use this system.

3. Developing human resources and training programs in the same field.

4. To include study of this system in more details in the syllabi of agricultural engineering departments in Sudanese universities as main source of manpower for agricultural sector.

5. Importance of evaluating performance of centre pivot system (water application efficiency and uniformity of water distribution) by specialists to address shortcomings of irrigation network in a timely manner and identify problems arising from design or operation. Evaluation must be done periodically to address problems in a timely manner.

6. Continue to conduct further field studies to evaluate performance of centre pivot system in the State, especially since the examined machines are still relatively new.

\section{Acknowledgements}

The author thanks both of Mr. Osman Abdelmawla Mohammed and Mr. Hussein Salih Hussein for their efforts in distribution and collection of questionnaires.

\section{References}

[1] Israelsen O. W. and Hansen V. E. 1965. Irrigation Principles and Practices. John Willey and Sons Inc., New York.

[2] Jensen M. E. 1983. Design and Operation of Farm Irrigation Systems. ASAE, Colorado.

[3] Li J. 1997. Effect of Pressure and Nozzle Shape on the Characteristics of Sprinkler Droplet Spectra. J. Agric. Eng. Res., 66, 15-21.

[4] Central Bureau of Statistics. 2009. $5^{\text {th }}$ Sudan Population and Housing Census- 2008: Priority Results (Northern State). Central Bureau of Statistics, Sudan.
[5] AOAD. 2002. Studying Methods of Developing Surface Irrigation and Drainage in the Arab Countries (in Arabic) [online], [cited Nov 2017]. Available at: http://yemennic.info/contents/Agric/Studies/13.pdf.

[6] Al-Ghobari H. M. 2007. Evaluation the Performance and Modification of Centre Pivot Irrigation Systems under Saudi Arabia Conditions (in Arabic). King Abdel Aziz City for Science and Technology, Saudi Arabia.

[7] Kara T., Ekmekci E. and Apan M. 2008. Determining the Uniformity Coefficient and Water Distribution Characteristics of some Sprinklers. Pakistan Journal of Biological Science, 11(2), 214-219.

[8] Brown P. 2008. Flood vs. Pivot Irrigation for Forage Crops: What Are the Advantages and Disadvantages?. In: Proceedings, California alfalfa and forage symposium and western seed conference, 2- 4 December, 2008, San Diego, CA [online], [cited Nov 2017]. Available at: http://alfalfa.ucdavis.edu/+symposium/.../2008/08-141.pdf.

[9] Threadgill E. D. 1985. Chemigation via Sprinkler Irrigation: Current Status and Future Development. Applied Eng. In Agric., 1(1), 16-23.

[10] Al-Ghobari H. M. 2006. Effect of Maintenance on the Performance of Sprinkler Irrigation Systems and Irrigation Water Conservation. Res. Bult. No. 141, Food Sci. and Agric. Res. Center, King Saud University, Saudi Arabia.

[11] Ebeidalla M. I. 2008. Performance and Irrigation Scheduling of Centre-Pivot Systems in River Nile State (Sudan). M. Sc. Thesis, University of Khartoum, Sudan.

[12] Mc Cann I. And Adkins J. 2007. Centre-Pivot Irrigation System Evaluations in Delaware: Preliminary Results. MidAtlantic Grain and Forage Journal, 10, 6-8.

[13] Elamoud A. I. 2002. Rationalization in Palm Irrigation (in Arabic). Faculty of Agriculture, King Saud University, Saudi Arabia.

[14] Elhassan Z. A. 2008. Assembling and Performance Evaluation of Centre Pivot Irrigation System New Hamdab Irrigation Project, Northern State, Sudan. M. Sc. Thesis, University of Khartoum, Sudan.

[15] Elkheir M. T. 2010. Evaluation of Operation Speed Effect on Centre Pivot Irrigation System Performance- a Case Study of Elwaha and Elzahra Project in Northern State (Sudan). M. Sc. Thesis, Sudan University of Science and Technologies, Sudan.

[16] Evans R. G. 2001. Centre Pivot Irrigation (Research Report). USDA- Agriculture Research Service. Sidney, MT, USA.

[17] Salih S. A. 2013. Evaluation of Speed Effect on Center-Pivot Irrigation Systems Performance at Waha Project under Sudan North State conditions. International conference on civil and architecture engineering (ICCA'2013) May 6- 7, 2013, Kuala Lumpur, Malaysia. 